\title{
Perebrat'sja and peremestit'sja
}

\author{
Natalia Pimenova \\ HSE University / 21/4 Staraya Basmannaya \\ Ulitsa, Building 1, 105066 Moscow \\ n_pimenova@yahoo.com
}

\begin{abstract}
The paper deals with contexts and synonymy of the Russian verbs perebrat'sja and peremestit'sja including new usages reflected in corpora. Subtle semantic and pragmatic differences assosiated with these verbs are analyzed. In the paper it is shown, that interpretation of verbs is inferred by context and can depend on animacy, grammatical features of nouns, physical features of the moving thing and path, manner of moving and even on benefits of moving. Perebrat'sja can implicate a longer distance, benefits of the new location (benefits for animate things and usefulness for inanimate things). Besides of the implication of a difficult path/ground the verb has a usage that includes the idea of motion with that of discreteness (motion in stages). The idea of a difficult path/ground can be neutralized for some agents (insects, spiders) because of the manner of their moving. Perebrat'sja can not be used for real things, persons and events moving into virtual worlds or between virtual worlds. However, such usage is possible for nouns denoting objects created in a virtual world.
\end{abstract}

Keywords: verbs of motion; synonymy; semantics; pragmatics

DOI: $10.28995 / 2075-7182-2021-20-1170-1179$

\section{Перебраться и переместиться}

\author{
Пименова Наталья \\ Национальный исследовательский \\ университет «Высшая школа экономики» / \\ 105066 Москва, Старая Басманная \\ улица 21/4, строение 1 \\ n_pimenova@yahoo.com
}

\begin{abstract}
Аннотация
В статье рассматриваются констексты и синонимия русских глаголов перебираться и перемещзаться, включая новые случаи употребления, фиксируемые в корпусах; анализируются тонкие семантические и прагматические различия, связанные с глаголами. Демонстрируется, как интерпретация глаголов зависит от контекста и от таких параметров как одушевленность, грамматические признаки имени, физические свойства движущегося объекта и свойства пути, способ движения и целесообразность перемещения. Перебраться может имплицировать более длинную дистанцию и выгодность новой локации (выгодность для одушевленных объектов и целесообразность - для неодушевленных). Глагол способен не только имплицировать сложность пути, но и употребляться в контекстах, связанных с представлением о дискретности движения (поэтапном перемещении). Импликация 'сложности пути' может нейтрализовываться для некоторых субъектов, обладающих специфическим способом перемещения (насекомые, пауки). Перебраться не используется для реальных объектов и событий, перемещающихся в виртуальный мир или между виртуальными мирами, од-нако такое употребление глагола оказывается возможным для имен, обозначающих объекты, созданные в виртуальном мире.
\end{abstract}

Ключевые слова: глаголы движения; синонимия; семантика; прагматика. 


\section{1 Введение}

Обозначая изменение локации, глаголы перебраться и переместиться могут быть синонимичными во многих контекстах. Однако даже при общей семантике 'передвижения' и при реализации идентичных семантических валентностей они проявляют сложные дифференциации, которые не фиксируются в словарях. Цель данной работы - определить, при каких базовых условиях возникает, а при каких блокируется синонимия (ср. иентр циклона переместился/ перебрался на север, иентр тяжести переместился/ *nеребрался на десять сантиметров; человек переместился/ 'перебрался на сантиметр вправо) и определить, какие семантические и прагматические компоненты вступают при этом в действие.

\section{2 Общие замечания}

Переместиться и перебраться представляют собой глаголы движения в широком понимания термина, т.е. глаголы со смысловым компонентом 'перемещаясь, перестать находиться в некотором месте' и/или 'перемещаясь, начать находиться в некотором месте'.

Словари стабильно фиксируют значение 'преодоления преграды', свойственное перебратьcя, а также частотные лексикализованные значения глаголов. Ср. в [СРЯ 1999]:

Перебраться. Переправляться, переходить через что-л. / Переселяться, переезжать из одного места на другое./ Пересаживаться или забираться на другое место.

Переместиться. Передвинуться, занять другое место, изменить свое местоположение./ Изменить свое местопребывание, перейти, переехать куда-л.

Сходные дефиниции даются и в других словарях; при этом не отмечаются новые случаи синонимии, фиксируемые в корпусе, ср. Капитанская повязка перебралась на руку Майкона; Капитанская повязка переместилась на плечо Вальдеса (после замены игрока на поле).

Основное значение перебраться: преодоление преграды, - реализуется в употреблениях: $n е$ -

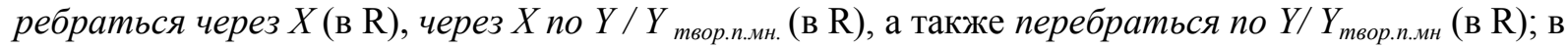
последнем случае сам $Y$ обозначает сложный путь (препятствие). Перемещаться через $X$ и по $Y$ можно с трудом или легко (т.е. преодолевая трудности), но это требует определенного усилия или внимания. Ср.: перебираться через реку, дорогу, забор; по ухабам, по неокрепшему льду, по слякоти, по остовам моста, по упавшему дереву; оврагами, тропами и т.п. Вариант 'сложного пути' - усложнение ожидаемой (рутинной) траектории: перебирался дворами, вдоль стенки и Т.П.

Для всей группы приставочных глаголов с основой -браться/ -бираться (вbl-, за-, до-, nере-) была отмечена «идея затрудненности перемещения» [Зализняк 2000: 32], интуитивно ясная для носителей языка [Левонтина 2016]. Так, добираться связано с представлениями 'далеко и/ или трудно' [Зализняк 2000: 33] и ассоциируется с особыми усилиями или сложным алгоритмом [Левонтина 2016], перебираться связывается не только с идеей преодоления препятствия, но и с представлением о продолжительности процесса [Левонтина 2016]. Однако те или иные импликации могут по-разному проявляться в различных употреблениях конкретного глагола. Так, добрался до кровати очевидным образом имплицирует 'с трудом', а перебрался на кровать (со стула) вне контекста такой импликации не имеет; импликация 'медленности' и 'затрудненности' может сниматься при значении 'пересечения' (перебрался через полосу) и т.п.

Сравнение перебраться с глаголом переместиться, который, как очевидно, имеет более нейтральную в отношении способа действия основу, позволяет выделить контрастные контексты, в которых проявляются специфические значения и импликации глагола перебраться, а также обнаружить некоторые эффекты, которые не описывались ранее. ${ }^{1}$

Ядерные употребления перебраться (через, по, тв.п.), где глагол сочетается с существительным, которое само по себе обозначает преграду или сложный путь, при этом могут не рассматриваться.

\footnotetext{
${ }^{1}$ В ходе работы производился системный анализ вхождений в «Национальном корпусе русского языка», в корпусе Russian mixed corpus, а также сплошной и целевой поиск с помощью поисковика Google.
} 
Отметим, что конкретный способ перемещения не кодируется ни одним, ни другим глаголом, а кодирование «маршрута» осуществляется одной приставкой пере-.

Реализацию у перебраться основных семантических валентностей, характерных для глаголов движения, можно проиллюстрировать в форме таблицы, в которую введены главные параметры, стандартно учитываемые при анализе глаголов движения в многочисленных работах о глаголах перемещения, cp. [Talmy 1975, 2007, Рахилина 1996.] и др.:

\begin{tabular}{|l|l|c|c|c|}
\hline & Перебраться, сов. вид & $\begin{array}{l}\text { Путь (по, через, } \\
\text { твор.п. без предло- } \\
\text { га) }\end{array}$ & $\begin{array}{l}\text { Исходная точка } \\
\text { Q }\end{array}$ & $\begin{array}{l}\text { Конечная точка } \\
\text { R }\end{array}$ \\
\hline 1. & \multicolumn{1}{|c|}{$+\left(^{+}\right.$} \\
\hline 2. & $(+)$ & $(+)$ & + \\
\hline 3. & $\begin{array}{l}\text { Режим наблюдения, наблю- } \\
\text { датель в конечной точке или } \\
\text { видит конечную точку }\end{array}$ & $(+)$ & $(+)$ & - \\
\hline 4. & $\begin{array}{l}\text { Лексикализованное значение } \\
\text { переселиться }\end{array}$ & + & $(+)$ \\
\hline
\end{tabular}

Знак + обозначает возможность реализации единственной валентности, $(+)-$ возможность реализации дополнительной валентности. Как очевидно, глагол перебраться в значении глагола движения допускает употребление либо только с указанием пути, либо только с указанием R. Опции $(+)$ для каждого случая являются не связанными друг другом, т.е. могут быть реализованы независимо друг от друга. В режиме наблюдения R конечная точка может быть эксплицитно не выражена.

Параметры валентностей для значения ‘переселиться’ демонстрируют, что лексикализация отражается в радикальном изменении валентностных возможностей: в этом значении перебраться может употребляться с указанием только исходной точки, ср. Он перебрался из Москbы. Напротив, при нелексикализованном значении примеры * Он перебрался из сада возможны в сугубо специальных случаях, когда глагол перебраться в контексте реализует свою семантику 'преодолевать препятствие', 'перемещаться через что-то'.

При употреблении перебраться в несовершенном виде и для обозначения однократного действия вариант 3 (режим наблюдения R) не существует, остальные валентности реализуются так же.

В отличие от перебраться, переместиться не требует обязательного выражения параметров 'путь' ( $X$ перемещается), Q и R и может выступать в самостоятельном употреблении; все семантические валентности могут реализовываться независимо друг от друга.

Рассматриваемые далее случаи представляет собой употребления, где возможности синонимизации глаголов обусловлены не тем, выражены или не выражены валентности (реализуются идентичные валентности). Однако некоторые сложные семантические эффекты перебраться опосредованно связаны с его валентностными возможностями.

\section{3 Импликация пути: скорость и расстояние}

Импликации 'расстояния' и 'скорости' могут быть проанализированы на ряде примеров. Рассмотрим контекст из «Национального корпуса русского языка» (НКРЯ):

(1) Катя Лисунова со своей позиции била / но успела переместиться вратарь в ближний угол. [А.Симонов, С.Фролов. Спортивный репортаж: водное поло. Телеканал «Россия-2» (2011)]

Небольшая дистанция (ворота для водного поло небольшие) не является препятствием для использования глагола перебраться. Однако употребление перебраться модифицирует смысл предложения и становится возможным, если ко времени удара вратарь уже успела перейти в 
ближний угол. Иными словами, перебраться может имплицировать некоторое относительно продолжительное время преодоления: оно, как правило, не может быть мгновенным (с «человеческой» точки зрения), как после удара по воротам. Для переместиться, напротив, возможно обозначение сколь угодно мгновенного перемещения в пространстве и во времени (переместиться в другую эпоху, фантастическим образом переместиться в другую Вселенную и т.п.). Ср. также:

\section{Минутная стрелка перемещяается скачком.}

Импликация продолжительности перемещения, как в (1), нейтрализуется эксплицитным указанием на способ действия: Вратарь успела прыжком перебраться в ближний угол. Ср. пример:

(3) Нечто, во мгновенье ока, перебирается по комнате и заслоняет собой окно. [Валерий Седов. Погаси]

Перебраться в этом контексте, по сравнению с переместиться, создает другой эффект: несмотря на скорость, наблюдатель успевает заметить «трассу» передвижения и, возможно, какие-то «телодвижения» объекта (ср. п.7).

С помощью сравнения различных контекстов можно примерно определить, по каким относительным параметрам определяется релевантная для перебраться длина пути. По-видимому, в нормальном случае перебраться подразумевает перемещение на новое место, поэтому приемлемость контекстов убывает по мере того, как длина пути становится меньше размеров объекта по направлению движения. Напротив, переместиться обозначает любое перемещение в пространстве, так что длина пути оказывается нерелевантной:

(4) ... человек специально переместился на полкорпуса [машины] и прижался к разделительной, чтобы меня не пустить.

(5) Когда его усы уткнулись в препятствие, Мисти резко остановился, в удивлении потряс головой, переместился чуть правее и снова уткнулся усами в стекло [Форум о ремонте].

Чуть правее в контексте (5) имеет довольно точную абсолютную меру: описывается, как кот медленно перемещался вдоль дверей и трогал стекло лапой через каждые два сантиметра.

При приемлемости и частом употреблении обоих глаголов в сочетании перебраться/ переместиться чуть правее/ чуть левее обычные контексты не дают столь точных показателей дистанции, но, как правило, речь идет не о частичном смещении, а о передвижении на новое место.

В то же время показательно, что для неодушевленных объектов, имеющих константные пространственные границы, именно переместиться, а не перебраться, может обозначать не только смену локации, но и частичный сдвиг в пространстве. Так, пример (6) может обозначать как то, что скамейка была перенесена на новое место, так и то, что она, оставшись на прежнем месте, частично сдвинулась (синоним: сместилась), например, в результате, наезда автомобиля:

Скамейка переместилась вправо.

Для одушевленных агенсов, способных к целеполаганию, такое различие не наблюдается. Сомнительность примеров типа 'Человек в дверном проеме перебрался на сантиметр вправо снимается при некоторых условиях: новая локация, на сколь бы микроскопическом расстоянии от исходной точки она не находилась, должна быть для субъекта перемещения более целесообразной. Ср. пример:

(7) Пулемётчик переместился чуть вправо, выбрал удобную позищию. [Из воспоминаний Н.Ф. Коноплева]. 
В таком контексте может употребляться глагол перебраться, причем, если речь идет о затаившемся снайпере, то частичное смещение может измеряться лишь несколькими сантиметрами.

\section{4 Смена vs. расширение локации}

Так как для глагола перебраться в общем случае оказывается относительно важной длина пути, позволяющая занять объекту новое место, то его употреблению сопротивляются вторичные контексты, в которых идет речь о сдвиге во внешнем пространстве внутренних точек объекта либо о перераспределении внутренних параметров объекта.

В частности, именно с переместиться употребляется центр тяжести. Отметим, однако, что перебраться, наряду с переместиться, часто выступает в качестве предиката при таких сочетаниях как цеентр цииклона/ антициклона, поскольку движение во внешнем пространстве объектов циклон и антициклон может измеряться именно по 'центру' ('центр' - конституирующая часть циклона и антициклона, измеряемая по максимуму параметра давления).

Обратимся к контексту, в котором идет речь об изменении параметров объекта в отдельных точках его исходной локации:

(8) Из делового центра трафик переместился в спальные районы столищы (о популярности домашнего Интернета из-за перехода на удаленную работу).

'Трафик' в данном употреблении - это информация, проходящая по коммуникационным системам, а также количество этой информации. В сообщении речь идет о возросшем количестве информации в отдельных районах, которые и раньше имели доступ к Интернету; т.е. абстрактный объект 'трафик' не изменил свою локацию, изменились лишь его параметры на отдельных участках расположения.

Предложение Трафик домашнего интернета перебрался в спальные районы, напротив, будет означать, что в спальных районах домашнего интернета раньше не было, а теперь этот вид получения информации захватил новые области распространения. Иное чтение: 'трафик теперь есть в новых районах, а в прежних его больше нет' (значение полного перемещения в новое место), - не противоречит семантике и условиям употребления глагола перебраться, однако противоречит нашим знаниям о мире (трудно предположить, что в прежних районах этой услуги больше нет).

Это толкование можно сделать более приемлемым, изменив контекст. При употреблении слова трафик в значении 'автомобильное движение' предложение Трафик перебрался в спальные paйоны в качестве одного из значений получит искомое дополнительное прочтение: 'движение наблюдается в спальных районах, в других районах его больше нет' ('весь трафик в данное время переместился в спальные районы'). Предложение с переместился может иметь такое же чтение.

Реализация значений перебраться 'полностью сменить локацию, покинув исходную точку' и 'увеличить область распространения, не покидая исходной точки' регулируется и некоторыми параметрами объекта и семантическим классом имени.

Для объектов, имеющих константные пространственные границы, в контекстах реализуется значение 'поменять прежнее место расположения на новое', для объектов, не имеющих постоянных пространственных границ (в том числе для объектов с природной способностью к росту), реализуются оба значения. К объектам второго типа относятся, в частности, ржавчина, плесень, грибок:

$$
\text { Ржавчина успела перебраться и на двери. }
$$

Примеры на контраст семантики в предложениях с субъектами первого и второго типа:

(10) Кажется, будто неутомимый плющ перебрался из сада в комнату и обвился вокруг шторного карниза (плющ растет на прежнем месте, но разросся и визуально своими побегами зашел в пространство комнаты). 
(11) Скамейка перебралась ближе к дому (была перенесена на новое место, наблюдаем результат).

Сочетание имен ржавчина, плесень, грибок с предикатом перебраться представляет собой устойчивую коллокацию, однако в Google-поисковике можно найти и синонимичные примеры с переместиться:

(12) Заплесневевшие вещи опасны тем, что грибок быстро может переместиться на шкаф, прочую мебель и стены.

Фиксируются и примеры, где переместиться при таких подлежащих обозначает полную смену локации.

При конкретных именах во множественном числе или родовых именах (именах, обозначающих целиком весь класс объектов) возможны оба толкования и того, и другого глагола: и 'расширить область расположения' и 'полностью сменить локацию'. Ср. пример с синонимичным употреблением 'расширить ареал обитания’ двух глаголов:

(13) Гены бактерий позволили растениям переместиться на землю. Университет провиниии Альберта (Канада) провел международное исследование совместно с ученыли из Китая, Франции, Германии и России, чтобы понять, как растения смогли в процессе эволюиии перебраться из воды на сушу [«Агро в детялях», 19.04.2020].

\section{5 «Инобытие» объекта}

Дистрибуция перебраться и переместиться имеет результатом еще один примечательный эффект, который можно было бы назвать эффектом метафорического перемещения. Употребление в контекстах, где идет речь о перемещении не самого объекта, а его образа («двойника», аналога), т.е. о виртуальном инобытии объекта, оказывается уместным для переместиться. Например:

(14) «Брусиловский прорыв» спустя 100 лет переместился в Кубинку: День сухопутных войск России отметили масштабной исторической реконструкиией [«Реальное время», 03.10.2016].

Речь идет не о повторении исторического события, а о его театрализованном воссоздании. Употребление перебраться в таком предложении было бы возможно в случае, если бы сообщалось о переносе регулярного мероприятия (например, ежегодного) под названием «Брусиловский прорыв» в другое место.

Ср. другие примеры с инобытием объекта:

(15) Байкал «переместился» в виртуальную реальность. Уникальные 360-градусные съемки Байкальского биосферного заповедника будут доступны для школьников всего мира [Портал tvkinoradio.ru].

(16) Киану Ривз переместился из «Матрицьl» в Японию. [«Известия», 2013, http:// iz.ru/news/563364]

В примере (16) сообщается о выходе нового фильма, действие которого происходит в Японии («47 ронинов»), с участием Киану Ривза, т.е. о создании актером нового образа в другой действительности.

Напротив, если речь идет об объекте, созданном в виртуальной реальности, то использование перебраться для обозначения переноса в новую реальность становится возможным; ср. о персонаже, который впервые появился в книге: 
(17) Родившийся в 1960-х Чебурашка перебрался < .. > на экран еще до начала 1970-х. [Baсилий Степанов. Жизнь-чебурашка. Памяти Эдуарда Успенского, 2018]

Иными словами, имена данного типа ведут себя подобно родовым именам (именам, обозначающим целый класс объектов): они способны обозначать множество репликаций образа, и, соответственно, не полную смену его локации, а расширение сферы распространения.

\section{6 Целеполагание, целесообразность и контроль}

Для одушевленных агенсов семантика перебраться способна имплицировать бенефактивный компонент 'извлечения выгоды из расположения в новой (конечной) точке перемещения’ и элемент 'целеполагания'. Так, несмотря на реализацию ядерных значений '(значительное) перемещение в R', 'трудности передвижения', а также семантики 'постепенности' кажется странным употребление перебраться в предложении Рыбак на отколовщейся льдине *nеребрался / переместился в открытое море - если речь не идет о сознательно предпринятом действии при естественности фразы Льдина с рыбаком перебралась в открытое море. Противоречие возникает в результате того, что рыбак как субъект перемещения должен являться бенефициантом нового расположения. Подобные скрытые семантические конфликты возникают при появлении в роли $\mathrm{R}$ объектов, которые в обычных случаях выступают как препятствия, только преодолев которые, можно оказаться в нейтральной (более выгодной, «хорошей» [Зализняк 2000: 32]) локации.

Сравним также нестандартность фразы Перебрались на машине в канаву с водой при ее естественности в описании экстремального вождения (цель - выбрать наиболее сложный путь):

(18) Продолжение грязевых покатушек. На этот раз перебрались в канаву с водой, но проехать удалось не всем...

Роль инициирования перемещения при выборе глагола иллюстрирует следующий пример:

(19) Все произошло быстро, он предположил, что между ним и Бисеровым была борьба, в ходе которой они переместились в канаву. [Протокол суда].

Здесь нейтрализованы значение постепенности, целеполагания и фактор 'выгодности R' (драки переносятся в сложные места и случайно, и сознательно), и выбор переместиться вместо перебраться соответствует тому факту, что говорящий не помнит, чтобы он и его соперник произвели какие-либо действия, которые привели к попаданию в канаву (преодоление пространства не было инициировано). Сравним в контрасте Дерущиеся постепенно перебрались в коридор: не имея целью попасть в коридор, произвели ряд действий, которые привели к перемещению (Напомним замечание А.А.Зализняк об идее неподконтрольности перемещения, выражаемого родственным глаголом добраться [Зализняк 2000: 33]).

Напротив, в производных употреблениях, при обозначении неодушевленных объектов, nеребраться в прошедшем времени широко используется для фиксации результата перемещения, произошедшего благодаря некоторым действиям неизвестных или предполагаемых агенсов (сил, стихий, лиц):

(20) Сухой листок перебрался/ переместился в угол балкона (ветер подул).

Ср. синонимию двух глаголов в описаниях нового дизайна автомобилей (данные поисковика Google):

(21) Фирменный значок перебрался с решетки на капот. Изменился передний бампер.

(22) Значок переместился немного ниже капота, также изменился бампер. 
Эффект целесообразности в некоторых случаях срабатывает и для неодушевленных объектов. Это происходит, когда точка $\mathrm{R}$ представляет неправильное и непредусмотренное с прагматической точки зрения расположение объекта. Ср.:

(23) *B результате столкновения корпус деформировался, и значок перебрался ближе к бамперу.

*Шнур обгорел и перебрался на пол.

Такой семантический конфликт возможен для объектов, имеющих «функциональную» локацию, предполагающую умысел или целесообразность. При этом событие, приведшее к нарушению целесообразности, должно быть эксплицитно выражено, в противном случае в контексте может реализовываться значение 'неожиданного эффекта'. Ср. Шнур перебрался на пол (имплицируется: а) сполз; б) кто-то положил).

\section{7 Способ действия}

Особые параметры регулируют возможность употребления и семантические эффекты перебраться и переместиться при обозначении незавершенного действия (несовершенный вид при однократном действии) с реализацией единственной семантической валентности 'путь' (перебираться по, где имя не обозначает сложный путь).

Достаточно тривиальным представляется указание на импликацию препятствий, свойственную глаголу перебраться. Так, странно построенным кажется употребление перебираться в (25):

$$
\text { Автомобили а) перемещчаются / б) ?'перебираются по дороге. }
$$

Эффект снимается эксплицитными указаниями на трудности передвижения:

(26) Автомобили перебираются по дороге «вплавь», движению мешает и лёд на дне лужи. [Амур - инфо, 4.04.2013]

Иными словами, употребление перебраться без указания Q, R с предложной группой с по и именем, не обозначающим сложный для передвижения путь, лицензируется неестественным и потому затрудненным (медленным) способом перемещения, который может быть связан как с другими объективными трудностями пути, так и с состоянием субъекта перемещения: автомобиль передвигается вплавь, человек - ползком, держась за стены и т.д. Ср.:

(27) Моя мать жалуется на спутанную походку, перебирается по квартире, держась за стенки. [Медицинский форум].

(28) Как долго будет действовать наркоз? Она [кошка] толком не лежит и не ходит, а перебирается по квартире, как зомби. [Форум otvet.mail.ru].

Сравним в контрасте к (28) вопрос ветеринара: У Bac кошка перемещается/ ходит по квартире?

Однако перебираться по может быть связано и с представлением движения просто как составного, предполагающего последовательное перемещение от одной точки к другой (эффект дискретности):

(29) А Луша живет где-то в цветах и перебирается по квартире перебежками. [Форум о домашних собаках].

Такое употребление возвращает в концептуализацию перемещения невыраженные точки Q и $\mathrm{R}$, характерные для основных употреблений глагола: ситуация предстает как ряд перемещений 
от $\mathrm{Q}_{1,2 \ldots}$ к $\mathrm{R}_{1,2 . .}$ и может выражаться также эксплицитно, сочетаниями от $X \kappa Y$. Дискретное преодоление пути может быть связанным с затруднениями, но может и не быть таковым.

Признаки 'медленно' и 'постепенно'/ 'дискретно', видимо, открывают путь для сдвига в узусе к употреблениям перебираться (где) с другими предлогами (единичные примеры), ср.:

(30) За деревьями все зашелестело, огни кровожадных глаз горели в тени. Кто- то перебирался по веткам, кто-то - за деревьями и кустарниками. [Книга фанфиков. Паучьи сети.].

Имплицируется: двигался 'медленно’ и/или ‘двигался сквозь лес от дерева к дереву’ (синоним: пробирался).

Эффект дискретности реализуется и для неодушевленных объектов, движущихся под влиянием внешних сил. Так, глагол перебраться (по), по-видимому, неуместен для равноускоренного движения (ср. невозможность заменить глагол в частотном сочетании перемещаться по орбите при нейтрализации признака в Марс перебирается в зону Стрельйа с указанной точкой R). Cp. еще один пример:

(31) $У$ него просто не получается еще ровно на лесенку прикрепить квадратик, чтобы он перебирался по лесенке вниз. [https:// lucyandleo.ru/product/LL243-Gorka-nastennaya-TSirk-nagore]

В детской игрушке кубик, поворачиваясь, постепенно спускается по перекладинам. Лесенка представляет собой 'сложный путь', но помимо этого, перебирался (в отличие от перемещался, спускался) вызывает представление о ряде движений (отчасти как у существа, преодолевающего лестницу).

Особняком стоят примеры типа (32):

$$
\text { В соисети «ВК» появилось видео, на котором крупный паук перебирается по стене. }
$$

'Движется медленно, и/ или по сложной поверхности' - это лишь одно возможное чтение, другое же парадоксальным образом противоположно: поверхность может сколь угодно удобной для передвижения, а паук может передвигаться быстро и равномерно. Нейтрализация компонентов 'сложность пути' и 'дискретность', вероятно, происходит в этом случае благодаря связи перебираться с перебирать 'делать частые короткие движения (пальцами, ногами) ${ }^{2}$ [Ожегов, Шведова 1997]. Такая нейтрализация действует для объектов, для которых перемещение с помощью «частых коротких движений» (конечностей) является естественным способом передвижения (насекомые, пауки).

\section{8 Выводы}

Итак, сложные эффекты рассмотренных глаголов возникают в тексте, под влиянием различных семантических и прагматических параметров, а также знаний о мире. На интерпретацию глаголов влияют одушевленность, класс имени, физические свойства объекта и пути, способ и целесообразность перемещения. Перебраться демонстрирует больше ограничений на использование, которые сложным образом связаны с ориентацией на $\mathrm{R}$ и семантику преодоления препятствий. Отметим, что большинство рассмотренных пограничных примеров не фиксируется в корпусах, что не позволяет провести анализ словоупотреблений классическими корпусными методами.

\section{References}

[1] Leipzig Corpora Collection: Russian mixed corpus based on material from 2013// Leipzig Corpora Collection, Dataset, Access mode: http://corpora.uni-leipzig.de? corpusId=rus_mixed_2013

[2] Talmy Leonard. Semantics and Syntax of motion // Kimball J. (ed.). Syntax and Semantics 4. - New York: Academic Press, 1975. - P. 181-238.

\footnotetext{
${ }^{2}$ В определенном смысле эта периодичность движений тоже представляет собой дискретность действия.
} 
[3] Talmy Leonard. Lexical typologies // Shopen Th. (ed.). Language typology and syntactic description, Vol. 3: Grammatical categories and the lexicon. - Cambridge: University press, 2007. - P.66-169.

[4] Большой толковый словарь русского языка. Гл. ред. С.А.Кузнецов. СПб.: Норинт, 1998. - В авторской редакции 2014 г.

[5] Ефремова Т. Ф. Современный толковый словарь русского языка: В 3 т. - М.: АСТ, Астрель, Харвест, 2006.

[6] Зализняк А.А. (2000). Преодоление пространства в русской языковой картине мира: глагол добираться // Логический анализ языка: Языки пространств. Н.Д.Арутюнова, И.Б.Левонтина (отв.ред.). - М.: Языки русской культуры. С.30-37.

[7] Левонтина И.Б. (2016). Охота к перемене мест // О чем речь. - М.: ACT Corpus. C. 152-156.

[8] Ожегов С. И., Шведова Н. Ю. Толковый словарь русского языка: 80000 слов и фразеологических выражений. - М.: Азбуковник, 1997.

[9] Рахилина Е.В. (1996). Локативность и вопрос // Теория функциональной грамматики. Локативность. Бытийность. Посессивность. Обусловленность. - СПб: Наука. С.27-51.

[10] Русский семантический словарь. Толковый словарь, систематизированный по классам слов и значений. Российская академия наук. Ин-т рус. яз. им. В. В. Виноградова; Под общей ред. Н. Ю. Шведовой. - М.: Азбуковник, 1998.

[11] СРЯ - Словарь русского языка. В 4-х т. РАН, Ин-т лингвистич. исследований; Под ред. А. П. Евгеньевой. - М.: Русский язык; Полиграфресурсы, 1999.

\section{References}

[1] Dictionary of the Russian Language [Slovar' russkogo yasyka], ed. by A.P.Evgenyeva. - Russian Academy of Sciences, Moscow: Russian language, Poligrafresursy, 1999. - Vol. 1-4

[2] Efremova T.F., Modern Dictionary of the Russian Language [Sovremennyi tolkovyi slovar' russkogo yasyka]. - Moscow: AST, Astrel, Harvest, 2006. - Vol. 1-3

[3] Great Dictionary of the Russian Language [Bol'shoi tolkovyj slovar' russkogo yasyka], ed. by S.A.Kuznetsov. - Moscow: Norint, 1998-2014.

[4] Leipzig Corpora Collection: Russian mixed corpus based on material from 2013// Leipzig Corpora Collection, Dataset. Access mode: http://corpora.uni-leipzig.de? corpusId=rus_mixed_2013

[5] Levontina I.B. (2016), Wanderlust [Ohota k peremene mest], What is about [O chem rech]. - Moscow, AST Corpus, pp. 152-156.

[6] Ozhegov S.I., Shvedova N.Y. Dictionary of the Russian Language: 80000 words and phraseological units [Tolkovyi slovar' russkogo yasyka: 80000 slov i vyrazhenii]. - Moscow: Azbukovnik,1997.

[7] Rakhilina E.V. (1996), Locativeness and question [Lokativnost' i vopros], Theory of Functional Grammar. Locativeness. Beingness. Posessivity. Causedness. [Teorija funkcional'noj gramatiki. Lokativnost'. Bytijnost'. Posessivnost'. Obuslovlennost']. - Saint Petersburg: Nauka, pp.27-51.

[8] Russian semantic dictionary. Lexicon systematized after word classes and meanings [Russkij semanticheskii slovar'. Tolkovyi slovar', sistematisirovannyi po klassam slov i znachenii], ed. by N.Y.Shvedova [Pod obshchei redakciei N.Y. Shvedovoi] - Russian Academy of Sciences, Moscow: Azbukovnik, 1998.

[9] Talmy Leonard. Semantics and Syntax of motion // Kimball J. (ed.). Syntax and Semantics 4. - New York: Academic Press, 1975. - P. 181-238.

[10] Talmy Leonard. Lexical typologies // Shopen Th. (ed.). Language typology and syntactic description, Vol. 3: Grammatical categories and the lexicon. - Cambridge: University press, 2007. - P.66-169.

[11] Zaliznyak A.A. (2000). Ovecoming of space in the Russian language picture of the world: the verb dobirat'sja [Preodolenije prostranstva v russkoi yasykovoi kartine mira: glagol dobirat'sja] // Logical analysis of language: Languages of space [Logicheskii analiz yasyka: Yasyki prostranstv], N.D.Arutjunova, I.B.Levontina (eds.), Moscow: Yasyki russkoj kul'tury, pp.30-37. 